Preprint

UCRL-JC-137736

\title{
Planning for an Integrated Research Experiment
}

J.J. Barnard't, L. E. Ahle', R. O. Bangerter', F. M. Bieniosek', C. M. Celata', A. Faltens' ${ }^{2}$ A. Friedman', D.P. Grote', I. Haber ${ }^{3}$, E. Henestroza ${ }^{2}$, R. A. Kishek', M. J. L. de Hoon', V. P. Karpenko', R. A. Kishek', J. W. Kwan', E. P. Lee', B.G. Logan', S.M. Lund', W.R. Meier', A. W. Molvik', T. C. Sangster', P. A. Seidl', W. M. Sharp ${ }^{1}$

1. Lawrence Livermore National Laboratory

2. Lawrence Berkeley National Laboratory

3. Naval Research Laboratory

4.University of Maryland

U.S. Department of Energy

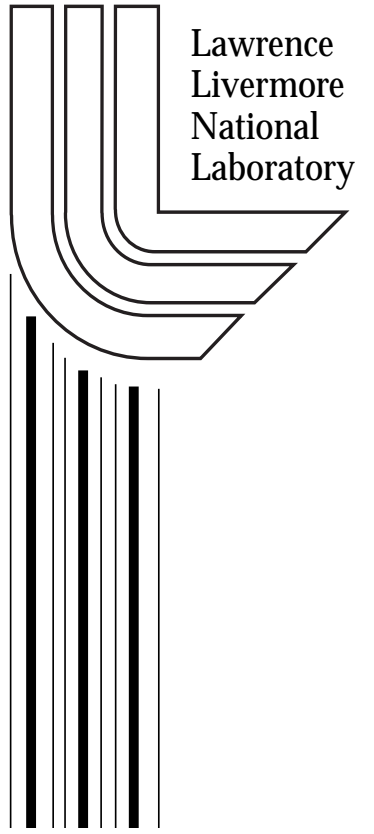

This article was submitted to the International Symposium on Heavy Ion Fusion, San Diego, CA, March 13-17, 2000

\section{May 20, 2000}




\section{DISCLAIMER}

This document was prepared as an account of work sponsored by an agency of the United States Government. Neither the United States Government nor the University of California nor any of their employees, makes any warranty, express or implied, or assumes any legal liability or responsibility for the accuracy, completeness, or usefulness of any information, apparatus, product, or process disclosed, or represents that its use would not infringe privately owned rights. Reference herein to any specific commercial product, process, or service by trade name, trademark, manufacturer, or otherwise, does not necessarily constitute or imply its endorsement, recommendation, or favoring by the United States Government or the University of California. The views and opinions of authors expressed herein do not necessarily state or reflect those of the United States Government or the University of California, and shall not be used for advertising or product endorsement purposes.

This is a preprint of a paper intended for publication in a journal or proceedings. Since changes may be made before publication, this preprint is made available with the understanding that it will not be cited or reproduced without the permission of the author.

This report has been reproduced directly from the best available copy.

Available electronically at http://www.doc.gov/bridge

Available for a processing fee to U.S. Department of Energy

And its contractors in paper from

U.S. Department of Energy

Office of Scientific and Technical Information

P.O. Box 62

Oak Ridge, TN 37831-0062

Telephone: (865) 576-8401

Facsimile: (865) 576-5728

E-mail: reports@adonis.osti.gov

Available for the sale to the public from

U.S. Department of Commerce

National Technical Information Service

5285 Port Royal Road

Springfield, VA 22161

Telephone: (800) 553-6847

Facsimile: (703) 605-6900

E-mail: orders@ntis.fedworld.gov

Online ordering: http:/ / www.ntis.gov/ordering.htm

\section{OR}

Lawrence Livermore National Laboratory

Technical Information Department's Digital Library

http: / / www.llnl.gov/tid/Library.html 


\title{
Planning for an Integrated Research Experiment ${ }^{*}$
}

J.J. Barnard ${ }^{1+}$, L. E. Ahle ${ }^{1}$, R. O. Bangerter ${ }^{2}$, F. M. Bieniosek ${ }^{2}$, C. M. Celata ${ }^{2}$, A. Faltens ${ }^{2}, \quad$ A. Friedman ${ }^{1}$, D.P. Grote ${ }^{1}$, I. Haber ${ }^{3}$, E. Henestroza ${ }^{2}$, R. A. Kishek ${ }^{4}$, M. J. L. de Hoon ${ }^{2}$, V. P. Karpenko ${ }^{1}$, R. A. Kishek ${ }^{4}$, J. W. Kwan' ${ }^{2}$ E. P. Lee ${ }^{2}$, B.G. Logan ${ }^{1}$, S.M. Lund ${ }^{1}$, W.R. Meier ${ }^{1}$, A. W. Molvik ${ }^{1}$, T. C. Sangster ${ }^{1}$, P. A. Seidl ${ }^{2}$, W. M. Sharp ${ }^{1}$

${ }^{1}$ Lawrence Livermore National Laboratory, P.O. Box 808, Livermore, California 94551 USA

${ }^{2}$ Lawrence Berkeley National Laboratory, Berkeley, California 94720 USA

${ }^{3}$ Naval Research Laboratory, Washington, D.C.20375, ${ }^{4}$ University of Md., College Park, Md. 20742

\begin{abstract}
We describe the goals and research program leading to the Heavy Ion Integrated Research Experiment (IRE). We review the basic constraints which lead to a design and give examples of parameters and capabilities of an IRE. We also show design tradeoffs generated by the systems code IBEAM.
\end{abstract}

Keywords: Fusion; Heavy Ion; Inertial fusion; Driver; Accelerator; Systems model

\section{Introduction}

The Integrated Research Experiment (IRE), a major step in the U.S. inertial fusion energy (IFE) program, will play a critical role in the development of IFE. The IRE must produce sufficient confidence to design and build an Engineering Test Facility (ETF), the final step towards an IFE demonstration power plant. The heavy ion IRE conceptual design effort is projected to begin in about two years (Spring 2002), but preliminary design examples have already been generated as computational models to develop simulation tools, and to explore parameters for possible high energy density experiments.

In section II, we review the goals of the IRE, which set the scale for the project. In section III, we give a brief overview of the research program that is laying the scientific and technological groundwork for the accelerator. In section IV, we outline the analysis leading to an example design which we are using as a testbed for our simulation tools. Finally, in section V we give illustrative results from the systems code IBEAM.

- *Work performed under the auspices of the US Department of Energy under contract DE-AO33-76F0098 at University of California LBNL, contract W-7405-ENG-48 at University of California LLNL, contract DEA102-93ER40799 at NRL, and contract DE-FG02-92ER54178 at U. Md.

- $\quad \dagger$ Corresponding author: Tel: 510-486-6124; email: jjbarnard@1lnl.gov 


\section{Goals and scale of the IRE}

The overriding goal of the IRE, together with target results from the U.S. Inertial Confinement Fusion program and progress on IFE chamber and target technology, is to provide the scientific and technological basis to proceed the ETF. The ETF will integrate all the major systems needed for an IFE power plant (driver, target production and injection, fusion chamber and heat removal). The ETF will demonstrate high rep-rate operation at low fusion yield (of order $30 \mathrm{MJ}$ ) and may include exploration of higher gain and yield targets. In order to meet the overriding goal, there are three general areas where the basis provided by the IRE must be solid: 1 . Accelerator physics; 2 . Chamber transport and final focus; and 3. Ion beam interaction with targets.

The accelerator physics basis includes all beam dynamics questions at driver scale, including emittance growth, halo formation, pulse compression, multiple beam effects, and "beam loading" (the effects of the beam itself on the driving circuitry, and ultimately back onto the beam). The IRE will also be, as its name indicates, an integrated system demonstration, from beam injector to target. Demonstrating the chamber transport and final focus basis for heavy ion fusion requires the ability to focus the beam at the target. This will entail testing several candidate methods for final focus including some that require beam neutralization. The IRE must also validate beam stability in the chamber (demonstrate absence of instabilities such as two-stream instability, filamentation, etc., or show that those that do exist are benign). Also, the effects of stripping of beam ions by chamber gas and photoionization of gas and beam by target X-rays must be shown to be quantitatively understood. Finally the IRE will study ion beam interaction with targets, including volumetric heating of matter (unique to ions) and ion stopping in dense plasmas, both of which are unobtainable from laser facilities, and needed to ensure target designs are well calibrated.

These overall goals lead to quantitative technical goals and an overall scale of the accelerator. Demonstration of an understanding of long-term transverse and longitudinal beam dynamics requires hundreds of lattice periods. In order for beam loading to have effects similar to those in a driver the total current at the end of the accelerator must be greater than of order $100 \mathrm{~A}$, a significant fraction of the total induction module current. This large total current will require tens of beamlets. To enable definitive focusing experiments from a variety of focusing modes, the ion energy must be greater than of order $100 \mathrm{MeV}$, the final generalized perveance must be at least that of a driver $\left(10^{-5}\right.$ to $\left.10^{-4}\right)$, and the normalized emittance $\varepsilon_{\mathrm{N}}$ must be less than about $5 \pi \mathrm{mm}$-mrad. Validating beam-target interaction physics requires a flux greater than of order $3 \times 10^{12} \mathrm{~W} / \mathrm{cm}^{2}$, and multi-kJ in the pulse, in order to heat matter to the $50 \mathrm{eV}$ range or greater. As the required capabilities of the beams are better understood, the exact scale of the accelerator will emerge. 
Further, it would be desirable (but not essential) for the IRE to serve as the front end of the ETF. This may require reconfiguration (since near term goals may require lighter ion masses or different pulse durations than a driver), possible relocation, and durable components. Finally, final energies of 100 's of $\mathrm{MeV}$, and currents of 10's of Amperes/beam at the end of the accelerator are required to meet the ultimate goal of providing a single intermediate step between the near term experiments ( $\sim$ few $\mathrm{MeV}, 1$ Ampere/beam) and the ETF $\left(\sim\right.$ few $\mathrm{GeV}, \sim 10^{2}$ Ampere/beam at end of accelerator). A smaller scale would lead to a larger extrapolation from IRE to ETF.

\section{Overview of research program in preparation for an IRE}

The preparation for an IRE and long term driver feasibility research drive the near term research program. See ref.[1] for a more detailed discussion of the U.S. Heavy Ion Fusion Program. The current "Phase I" program has two new experiments among its research goals: 1 . A high-current prototype injector module (leading to 10 to $100 \mathrm{~A}$, at about $1 \mathrm{~A} /$ beam, and leading to an IRE injector with a cost of less than of order $\$ 20 \mathrm{M}$ ) (cf. [2]); and 2. A high-current transport and focusing experiment (HCX) (a 1 A single beam machine designed to study the transport limits of beams with driver-scale line charge density) (cf. [3]). The Phase I program also has an enabling technology component, that is focused on the development of four critical components: 1 . Multiple- beam quadrupole arrays (with a total cost goal of less than $\$ 10 / \mathrm{kA}-\mathrm{m}$ of superconducting wire); 2 . Cast insulators (with a cost goal of less than $\$ 0.01 / \mathrm{V}$ of average accelerating gradient); 3 . Ferromagnetic materials, (with a cost goal of $\$ 5-10 / \mathrm{kg}$ ), and 4 . Pulsers (with a cost goal of less than $10^{-5} \$ / \mathrm{W}$ for switches, and less than $\$ 20 / \mathrm{J}$ for stored energy). The final element of the Phase I program is development of an end-to-end simulation capability for both the IRE and full-scale drivers. This goal requires simulating a beam from the source, transporting it through the injector, accelerator, drift-compression section, final focus magnets, and target chamber, and then using the final distribution function of the beam at the focal spot as the input into the radiation-hydro code used to simulate the target dynamics. As currently envisioned, different codes would handle the accelerator and target chamber, with the results from the accelerator section serving as input into the chamber simulations. See ref. [4] and ref. [5] for more detailed discussions of the simulation program.

\section{Example IRE Design}

Early designs of the IRE have been based on analytic scaling laws [6,7], which we describe below. The designs grew out of earlier work on plans for the so-called High Temperature Experiment (HTE) (ref. [8]). These initial designs were intended for use as test-beds for simulations and to estimate final capabilities at the focal spot. It 
should be emphasized that these designs are starting points, and the discussions that follow are intended to give a general understanding of the scaling; detailed designs will result from more comprehensive systems studies. From the semi-analytic designs, a program written in the Python interpreted language specifies detailed placements of system components that are required for simulations in the ParticleIn-Cell (PIC) code WARP. A single slice of the beam can be simulated using the 2D version of the code WARP2D, and emittance growth, halo formation, and sensitivities to accelerator errors can be studied. To simulate the full 3D dynamics of the beam, accelerating voltage waveforms must first be generated. At present the transverse envelope/longitudinal fluid code CIRCE is used to generate these waveforms which are then fed to the 3D PIC code WARP3d. See ref. [4].

In an induction linac, several limits constrain the design. The phase advance per lattice period, $\sigma_{0}$, must be kept less than about $85^{\circ}$ to avoid envelope/lattice instabilities. For magnetic focusing, the phase advance is related approximately [9] to the magnetic field gradient $B^{\prime}$ by $\left(2\left[1-\cos \sigma_{0}\right]\right)^{1 / 2}=\eta B^{\prime} L^{2}(1-2 \eta / 3)^{1 / 2} /[B \rho]$, where $\eta$ is the quad occupancy, $L$ is the half-lattice period, and [B $\rho$ ] is the ion rigidity. For electric quadrupolar focusing, in the expression for $\sigma_{0^{\prime}} \mathrm{B}^{\prime}$ is replaced by $E^{\prime} / v$ where $E^{\prime}$ is the transverse electric field gradient, and $v$ is the ion longitudinal velocity.

Space charge is limited by external focusing, described by the relation $K<\left(\sigma_{0} a\right.$ $/ 2 L)^{2}$ where $K$ is the generalized perveance (proportional to line charge density $\lambda$ over ion voltage $\mathrm{V}$ [i.e. ion energy over ion charge] for a non-relativistic beam), and $a$ is the average beam radius.

A third limit is the velocity tilt, $\Delta \mathrm{v} / \mathrm{v}$, which for electrostatic quads must be less than about 0.3 to ensure that the tail radius and head $\sigma_{0}$ are not excessive and to minimize mismatches at the head and tail of beam. Here $\Delta v$ is the difference between tail and head velocity at a fixed position along the accelerator. Since $\sigma_{0}$ is a more sensitive function of velocity for electric than for magnetic quads (scaling roughly as $1 / \mathrm{v}^{2}$ for electric focusing and $1 / \mathrm{v}$ for magnetic focusing), magnetic focusing allows a considerably larger $\Delta v / v$. Simulations will be carried out to establish the exact limit on $\Delta \mathrm{v} / \mathrm{v}$ for magnetic quadrupoles. The velocity tilt is given approximately by $\Delta \mathrm{v}=(\mathrm{dV} / \mathrm{ds})(1 / \mathrm{v})(1 / 2-[\mathrm{V} / \mathrm{l}] \mathrm{dl} / \mathrm{dV})$, where $l$ is the bunch length of the flat-top of the beam and $1 / \mathrm{v}$ is the flat-top pulse duration. This expression is valid when the acceleration gradient length is much longer than the bunch length of the beam, as is true here. Note that for an accelerating beam, a velocity tilt is required to maintan a beam of constant bunch length $(\mathrm{dl} / \mathrm{dV}=0)$.

Another practical limit encountered by the linac designer is the number of Voltseconds per meter $(\mathrm{dV} / \mathrm{ds}) \mathrm{l} / \mathrm{v}$, where $\mathrm{dV} / \mathrm{ds}$ is the average accelerating 
gradient. This limit arises because for each core the volt-second product is given by, $V \Delta t=\eta_{\mathrm{cr}} \Delta \mathrm{BA}$ (from Faraday's law), where $\Delta \mathrm{t}$ is the voltage pulse duration, $\Delta B$ is allowed magnetic flux swing before saturation sets in, $\eta_{\mathrm{cr}}$ is the radial packing fraction of the ferromagnetic material, and $A$ is the cross-sectional core area. $A$ is given by $\eta_{\mathrm{cl}}\left(R_{\mathrm{o}}-R_{\mathrm{i}}\right) \mathrm{L}$, where $\eta_{\mathrm{cl}}$ is the longitudinal core occupancy, $R_{o}$ and $R_{i}$ are the outer and inner radii of the induction cores. Thus $(\mathrm{d} V / \mathrm{d} s) l / v$ is proportional to $R_{\mathrm{o}}-\mathrm{R}_{\mathrm{i}}$, which at present is taken to be less than approximately 1 to 1.5 meters. This translates into a limit on $(\mathrm{dV} / \mathrm{ds}) 1 / \mathrm{v}<\sim 1.3$ to $2.0 \mathrm{~V}-\mathrm{s} / \mathrm{m}$ for $\Delta \mathrm{B}=$ $2.5 \mathrm{~T}, \eta_{\mathrm{cr}}=0.8, \eta_{\mathrm{cl}}=0.8$, and $\Delta \mathrm{t} /(1 / \mathrm{v})=1.2$ to account for finite rise and fall times of current and voltage pulse.

A final practical limit in the accelerator is the average accelerating gradient $\mathrm{dV} / \mathrm{ds}$. Breakdown limits along insulators in the machine are currently assumed to limit the average acceleration to less than $\sim 1$ to $2 \mathrm{MV} / \mathrm{m}$. Insulator research and systems studies are aimed at extending and more precisely defining this limit.

We have obtained a rough design for a possible IRE [10]. It is composed of 32 beamlines of singly charged potassium, accelerated to $200 \mathrm{MeV}$. The initial pulse duration is $6.69 \mu \mathrm{s}$, and the final pulse energy summed over all 32 beamlines is 30 $\mathrm{kJ}$. It is composed of three main sections:

1. Electrostatic quadrupoles; constant bunch length.

2. Magnetic quadrupoles with bunch compression, constant volt-seconds per $\mathrm{m}$. 3. Magnetic quadrupoles; constant bunch length and maximum acceleration gradient. In addition, transitions between the sections are required. The scaling and values of parameters in this example (denoted the "reference IRE accelerator") are summarized in table I.

In the first section constant bunch length is assumed, $(\mathrm{dl} / \mathrm{dV}=0)$ and the line charge density $\lambda$ is also constant (at $0.27 \mu \mathrm{C} / \mathrm{m}$ ). The velocity tilt is held constant $(\Delta \mathrm{v} / \mathrm{v}=0.3)$ which leads to a scaling in that section such that the gradient $\mathrm{dV} / \mathrm{ds}$ $\sim \mathrm{V}$. The space charge limit implies $\mathrm{L} \sim \mathrm{V}^{1 / 2}$; and with a constant midpulse $\sigma_{0}$ (at $\left.54^{\circ}\right)$ and focusing gradient $E^{\prime}$, the occupancy $\eta$ is constant as well.

In the second section, the velocity tilt is such as to make acceleration and compression give equal contributions to the velocity tilt, yielding a bunch length $l$ that varies as $\mathrm{V}^{-1 / 2}$. In this section, the Volt-seconds per meter is limiting and held constant so that $\mathrm{dV} / \mathrm{ds} \sim \mathrm{V}$, as in section 1 . The space charge limit yields a half lattice period $\mathrm{L} \sim \mathrm{V}^{1 / 4}$. Constant $\sigma_{0}\left(\right.$ at $\left.70^{\circ}\right)$ at maximum $\mathrm{B}^{\prime}$ implies the quad occupancy $\eta$ is held constant $(0.33)$.

When the maximum gradient is reached, a third section is started in which the gradient is frozen at the maximum value $(\mathrm{dV} / \mathrm{ds}=1000 \mathrm{kV} / \mathrm{m})$. To avoid 
excessively large electric fields in the "ears," we also maintain a constant bunch length in this section. Constant bunch length, together with constant beam radius, yields a half lattice period scaling $\mathrm{L} \sim \mathrm{V}^{1 / 2}$ and a constant velocity tilt $\Delta \mathrm{v} / \mathrm{v}$. In this, the longest of the three sections it is convenient to also freeze magnet length, assuming a cost benefit will accrue from such standardization. The scaling on the occupancy then follows the relation $\eta \sim \mathrm{V}^{-1 / 2}$; and the assumption of constant $\sigma_{0}$ requires the focusing gradient $B^{\prime} \sim 1 /(1-2 \eta / 3)^{1 / 2}$.

Table I. Scaling and summary of parameters for thereference IRE accelerator.

\begin{tabular}{|l|l|l|l|l|l|l|}
\hline & $\begin{array}{l}\text { Bunch } \\
\text { length } \\
1(\mathrm{~m})\end{array}$ & $\begin{array}{l}\text { Half } \\
\text { Lattice } \\
\text { Period L } \\
(\mathrm{m})\end{array}$ & $\begin{array}{l}\text { Current } \\
\text { per } \\
\text { beam } \\
\mathrm{I}(\mathrm{A})\end{array}$ & $\begin{array}{l}\text { Quad. } \\
\text { Occup. } \\
\eta\end{array}$ & $\begin{array}{l}\text { Acceler. } \\
\text { Grad.dV/ } \\
\mathrm{dz} \\
(\mathrm{kV} / \mathrm{m})\end{array}$ & $\begin{array}{l}\text { Focusing } \\
\text { Gradient } \\
\mathrm{B}^{\prime} \text { or E' }\end{array}$ \\
\hline $\mathrm{V}_{0}=1.6 \mathrm{MeV}$ & 18.8 & 0.21 & 0.77 & 0.65 & 55 & $\begin{array}{l}1.4 \times 10^{8} \\
\mathrm{~V} / \mathrm{m}^{2}\end{array}$ \\
\hline Electric focusing & const. & $\sim \mathrm{V}^{1 / 2}$ & $\sim \mathrm{V}^{1 / 2}$ & 0.65 & $\sim \mathrm{V}$ & $\begin{array}{l}1.4 \times 10^{8} \\
\mathrm{~V} / \mathrm{m}^{2}\end{array}$ \\
\hline $\mathrm{V}_{1}=9.4 \mathrm{MeV}$ & 18.8 & 0.5 & 1.87 & jump & 323 & jump \\
\hline $\begin{array}{l}\text { Magnetic focusing } \\
\text { (compression) }\end{array}$ & $\sim \mathrm{V}^{-1 / 2}$ & $\sim \mathrm{V}^{1 / 4}$ & $\sim \mathrm{V}$ & 0.33 & $\sim \mathrm{V}$ & $37 \mathrm{~T} / \mathrm{m}$ \\
\hline $\mathrm{V}_{2}=29.8 \mathrm{MeV}$ & 10.6 & 0.67 & 5.9 & 0.33 & 1000 & $37 \mathrm{~T} / \mathrm{m}$ \\
\hline $\begin{array}{l}\text { Magnetic focusing (const. } \\
\text { bunch length) }\end{array}$ & const. & $\sim \mathrm{V}^{1 / 2}$ & $\sim \mathrm{V}^{1 / 2}$ & $\sim \mathrm{V}^{1 / 2}$ & const. & $\begin{array}{l}\text { slow } \\
\text { variation }\end{array}$ \\
\hline $\mathrm{V}_{3}=200 \mathrm{MeV}$ & 10.6 & 1.73 & 15.3 & 0.127 & 1000 & $34.1 \mathrm{~T} / \mathrm{m}$ \\
\hline
\end{tabular}

Towards the end of the third accelerator section, as the beam is approaching 200 $\mathrm{MeV}$, a velocity tilt is placed upon the beam to longitudinally compress it in a drift compression section after the accelerator. Although we have not yet done detailed simulations of the IRE beam in the drift compression section, we have made analytic estimates to characterize the final beam parameters that could be achieved on target. The final peak line charge density $\lambda_{\mathrm{a}}$ at the output of the accelerator would be $0.73 \mu \mathrm{C} / \mathrm{m}$. (This is 1.5 times larger than the peak flat-top line charge density, to account for a parabolic density profile we assume in the analytic estimates.) The associated peak generalized perveance $K_{\mathrm{a}}$ is then $3.3 \times 10$

${ }^{5}$. We choose three different values of final pulse duration $\Delta \mathrm{t}_{\mathrm{f}}(5,10$, and $20 \mathrm{~ns})$ to estimate the final parameters. These are summarized in table II, below. Note that in the table that subscript " $\mathrm{f}$ " indicates parameters evaluated at the final focal spot, and subscript "a" indicates that it is to be evaluated at the end of the accelerator (prior to drift compression). 
Table II. Final beam and drift compression parameters for reference accelerator as a function of $\Delta t_{f}$

\begin{tabular}{|c|c|c|c|c|c|c|c|c|}
\hline \multirow[t]{3}{*}{$\begin{array}{l}\text { Final } \\
\text { pulse } \\
\text { duration } \\
\Delta \mathrm{t}_{\mathrm{f}}(\mathrm{ns})\end{array}$} & \multirow{3}{*}{$\begin{array}{l}\text { Compr } \\
\text { es-sion } \\
\text { ratio } \\
\text { C } \\
l_{\mathrm{a}} / \mathrm{l}_{\mathrm{f}}\end{array}$} & $\begin{array}{l}\text { Velocity } \\
\text { tilt } \\
(\Delta \mathrm{v} / \mathrm{v})_{\mathrm{a}}\end{array}$ & $\begin{array}{l}\text { Drift } \\
\text { length } \\
d_{\text {drift }}(\mathrm{m})\end{array}$ & $\begin{array}{l}\text { Energy } \\
\text { Flux } \\
\mathrm{F}\left(\mathrm{W} / \mathrm{cm}^{2}\right)\end{array}$ & \multicolumn{2}{|c|}{$\mathrm{k}_{\mathrm{B}} \mathrm{T}_{\max }(\mathrm{eV})$} & \multicolumn{2}{|c|}{$\mathrm{k}_{\mathrm{B}} \mathrm{T}_{\text {model }}(\mathrm{eV})$} \\
\hline & & $\begin{array}{c}{\left[8 \mathrm{~K}_{\mathrm{a} g}\right.} \\
(\mathrm{C}-1)]^{1 / 2}\end{array}$ & $\begin{array}{l}l_{\mathrm{a}}(1-1 / \mathrm{C}) / \\
\Delta \mathrm{v} / \mathrm{v}\end{array}$ & $\mathrm{E} /\left(\pi \mathrm{r}_{\mathrm{f}}^{2} \Delta \mathrm{t}_{\mathrm{f}}\right)$ & \multicolumn{2}{|c|}{$\mathrm{k}_{\mathrm{B}}(\mathrm{F} / \sigma)^{1 / 4}$} & \multicolumn{2}{|c|}{$\begin{array}{l}\text { (cf. ref. } \\
\text { [11]) }\end{array}$} \\
\hline & & & & & $\begin{array}{l}\mathrm{r}_{\mathrm{f}}=5 \\
\mathrm{~mm}\end{array}$ & $\begin{array}{l}\mathrm{r}_{\mathrm{f}}=2.5 \\
\mathrm{~mm}\end{array}$ & $\begin{array}{l}\mathrm{r}_{\mathrm{f}}=5 \\
\mathrm{~mm}\end{array}$ & $\begin{array}{l}\mathrm{r}_{\mathrm{f}}=2.5 \\
\mathrm{~mm}\end{array}$ \\
\hline 5 & 67 & 0.150 & 71.7 & $7.6 \times 10^{12}$ & 93 & 131 & 43 & 101 \\
\hline 10 & 33.5 & 0.106 & 101 & $3.8 \times 10^{12}$ & 78 & 110 & 43 & 95 \\
\hline 20 & 16.8 & 0.074 & 140 & $1.9 \times 10^{12}$ & 66 & 92 & 42 & 87 \\
\hline
\end{tabular}

In Table II, the longitudinal space charge factor $\mathrm{g} \equiv-4 \pi \varepsilon_{\mathrm{o}} \mathrm{E}_{\mathrm{z}} /\left(\lambda / \mathrm{z}^{\prime}\right) \cong 2 \ln \left(r_{\mathrm{p}} / a\right)$ was assumed to be $1.3, \mathrm{k}_{\mathrm{B}}$ is the Maxwell-Boltzmann constant, $\sigma$ is the StefanBoltzmann constant, $\mathrm{E}$ is the total pulse energy, and $\mathrm{z}^{\prime}$ is the longitudinal distance in the comoving beam frame. The compression ratio $C \equiv 1_{\mathrm{a}} / 1_{\mathrm{f}}$ is the ratio of the bunch length at the end of the accelerator to that at the target.

The final two columns in the table display estimates of the maximum spot temperature for the three different pulse durations. The quantity $\mathrm{k}_{\mathrm{B}} \mathrm{T}_{\max }$ is the temperature (in $\mathrm{eV}$ ) found from equating the energy flux $\mathrm{F}$ onto the target with the radiative flux from the target $\sigma \mathrm{T}^{4}$. A more detailed model in ref. [11] takes into consideration the energy required to heat the target. In this model, the temperature of the target evolves according to $\mathrm{R} d \varepsilon / \mathrm{dt}=\mathrm{F}-\sigma \mathrm{T}^{4}$, where $\mathrm{R}$ is the ion range (approximately $.012 \mathrm{~g} / \mathrm{cm}^{2}$ ) and $\varepsilon$ is the specific energy of the target material. In ref. [11], using the Raiser-Zeldovich approximation to calculate the ionization state of the matter, it was found that $\varepsilon$, in aluminum at relevant temperatures, was approximately given by: $\quad \varepsilon=7750 \mathrm{~J} / \mathrm{g}$ $\left(\mathrm{k}_{\mathrm{B}} \mathrm{T} / 1 \mathrm{eV}\right)^{1.5}\left(\rho / 1 \mathrm{~g} / \mathrm{cm}^{3}\right)^{0.12}$, where $\rho$ is the mass density of the target material. For the table we assume a felted aluminum target at a density of $0.1 \mathrm{~g} / \mathrm{cm}^{3}$. It can be seen that for a $5 \mathrm{~mm}$ spot, temperatures of order $43 \mathrm{eV}$ can be achieved, whereas one would need to achieve a $2.5 \mathrm{~mm}$ spot radius for $100 \mathrm{eV}$ temperatures. These calculated temperatures could be lower if hydrodynamic motion cools the spot or higher if radiation is trapped by means of opaque foils, or geometries (such as 
cylindrical hohlraums proposed for the ITEP TWAC experiments (ref. [12])) which focus the radiation. More detailed calculations are in progress.

Because the final ion velocity at the end of the accelerator is likely to be less than in a driver, the generalized perveance for the IRE is likely to be larger than it is in a driver. Since the generalized perveance indicates the importance of space charge relative to the kinetic energy of beam particles, it plays an important role in determining the focusability. To meet the $5 \mathrm{~mm}$ or smaller spot radius goal, for this example accelerator the beam must be neutralized.

To estimate the degree of neutralization required we consider the envelope equation when only space charge is included: $\mathrm{d}^{2} a / \mathrm{d} z^{2}=(1-f) K_{\mathrm{a}} C / a$. Here $a$ is the beam radius, and $f$ is the fraction of the beam space charge that has been neutralized. At the exit of the final magnet, where the beam radius has value $a_{\mathrm{o}^{\prime}}$ one integration of the envelope equation implies $f \cong 1-\theta^{2} /\left(2 K_{\mathrm{a}} C \ln \left(a_{d} / r_{f}\right)\right)$ where $\theta$ is the focusing half angle $\theta \cong a_{\mathrm{o}} / d$, and $d$ is the focal distance, which we assume to be $2 \mathrm{~m}$ for the IRE. Neutralization fractions between $89-97 \%$ (for final pulse duration $\Delta \mathrm{t}_{\mathrm{f}}$ between 20 and $5 \mathrm{~ns}$, respectively) are required for convergence angles less than or equal to $15 \mathrm{mrad}$. The neutralization fractions may be limited to values of order 1- $\alpha q m_{\mathrm{e}} /\left(C K_{\mathrm{a}} A m_{\mathrm{amu}}\right)$ [13] for electrons that are picked up axially, where $\alpha$ is between 1 and $4, m_{\mathrm{e}}$ and $m_{\text {amu }}$ are the electron mass and atomic mass unit, respectively, and $A$ is the ion mass in amu. For the worst case, $\alpha=4$, this would span the range $90-97 \%$ respectively. The two constraints on $f$ can be written $(A / q)>2\left(m_{\mathrm{e}} / A m_{\mathrm{amu}}\right) \alpha\left(\ln \left[\theta \mathrm{d} / \mathrm{r}_{\mathrm{f}}\right]\right) / \theta^{2} \cong 35$ for $\alpha=4$. The reference IRE parameters are thus consistent with this inequality, but detailed simulations of the neutralization process will, of course, be carried out for a variety of neutralization methods. Contributions to the spot size from the emittance $\delta r_{\varepsilon} \cong$ $\varepsilon_{\mathrm{n}} / \beta \theta$ and from chromatic aberrations (assuming uncorrected optics) $\delta r_{\delta \mathrm{p} / \mathrm{p}} \cong$ $6 \mathrm{~d} \theta \delta p / p$ must also be taken into consideration. A normalized emittance $\varepsilon_{\mathrm{n}}$ less than 3 to $5 \pi \mathrm{mm}$-mrad and momentum spread $\delta p / p$ less than $1 \%$ would satisfy the spot radius requirement of less than or equal to $5 \mathrm{~mm}$.

The upper end of the compression ratios proposed for this example IRE would exceed those that are required for a driver. One issue arising from a large compression ratio is the voltage variation allowed at each accelerating module and at the injector [14]. Since errors in the voltage waveforms at the $\mathrm{i}^{\text {th }}$ module, $\delta V_{\mathrm{i}}$ will get translated into longitudinal momentum variations $\delta p_{\mathrm{I}}=\left(p_{\mathrm{i}} / 2 V_{\mathrm{i}}\right) \delta V_{\mathrm{i}}$, a specification can be set on the allowed variation in the voltage waveforms. As the pulse length shortens, longitudinal phase space is conserved $\delta p_{\mathrm{i}} l_{\mathrm{i}}=\delta p_{\mathrm{a}} l_{\mathrm{a}}$, so the momentum variations increase. The larger the compression ratio, the larger the growth of the perturbation. At each module, a number of pulsers $\mathrm{N}_{\mathrm{p}}=V_{\mathrm{i}} / V_{\text {pulser }}$ add together, so that fluctuations add statistically, with $\delta V_{\mathrm{i}}=$ $\left(V_{\mathrm{i}} / V_{\text {pulser }}\right)^{1 / 2} \delta \mathrm{V}_{\text {pulser }}$. Here $\mathrm{V}_{\mathrm{i}}$ is the voltage increment at the ith module, and $\mathrm{V}_{\text {pulser }}$ 
is the pulser voltage, which we take to be $10 \mathrm{kV}$. Also, weighing each perturbation by the ratio of the bunchlength at each module $l_{\mathrm{i}}$, to its value at the end of the accelerator $l_{\mathrm{a}}$, we estimate the momentum variation at the end of the accelerator $\delta p_{\mathrm{a}} / p_{\mathrm{a}}$ :

$\left(\delta p_{\mathrm{a}} / p_{\mathrm{a}}\right)^{2}=$

$\Sigma(1 / 4)\left(V_{\mathrm{i}} V_{\text {pulser }} / V_{\mathrm{a}}^{2}\right)\left(\delta V_{\text {pulser }} / V_{\text {pulser }}\right)^{2}\left(\Delta t_{\mathrm{i}} / \Delta t_{\mathrm{a}}\right)^{2}+(1 / 4)\left(\delta V_{\text {injector }} / V_{\text {injector }}\right)^{2}\left(\Delta t_{\text {injector }} / \Delta t_{\mathrm{a}}\right)^{2}$ Here, the sum in the first term is over all acceleration modules, and the second term arises from injector voltage variations, weighted appropriately. Further compression in the drift section increases the momentum spread at the target $\delta p_{\mathrm{t}} / \mathrm{p}_{\mathrm{t}}$, such that $\delta p_{\mathrm{t}} / \mathrm{p}_{\mathrm{t}}=C \delta p_{\mathrm{a}} / \mathrm{p}_{\mathrm{a}}$. For a $\delta p_{\mathrm{t}} / \mathrm{p}_{\mathrm{t}}=0.01$, and equal contributions from pulser errors and injector voltage errors, this limits $\delta V_{\text {pulser }} / V_{\text {pulser }}=0.01$ to 0.03 , and $\delta V_{\text {injector }} / V_{\text {injector }}=0.001$ to 0.005 , for $C=67$ to 17 respectively.

Another concern is the robustness of the spot radius under variations in the onset of neutralization in the final chamber. The envelope equation in the final chamber is: $\mathrm{d}^{2} a / \mathrm{d} z^{2}=(1-f) K_{\mathrm{a}} C / a+\varepsilon^{2} / a^{3}$. If the neutralization point (location where $1-f$ approaches zero) is delayed by a distance $\delta l$, the spot radius will increase by an amount $\quad \delta \mathrm{r} \cong f K_{\mathrm{a}} C d\left(\delta l / a_{\mathrm{o}}\right)=4$ to $1 \mathrm{~mm}$, for $C=67$ to 17 respectively, and assuming that $\delta l / a_{\mathrm{o}}=1$. This uncertainty is largest for large $C K_{\mathrm{a}}$ and would be of greatest concern if $\delta 1$ were to be variable from pulse to pulse.

Another requirement in the transport of high line charge density beams is that the radial electric field of the beam does not cause breakdown at the beam pipe wall. This constraint is easily quantified from an estimate of the radial electric field $\mathrm{E}=\lambda /\left(2 \pi \varepsilon_{0} \mathrm{r}_{\mathrm{p}}\right)=16$ to $4 \mathrm{MV} / \mathrm{m}$ for $C=67$ to 17 respectively, and where the pipe radius $r_{p}=5 \mathrm{~cm}$. These values should be achievable, particularly over the duration of the short 5-20 ns pulse.

Finally, third order geometric aberrations are a concern for beams of convergence angles which may be needed for high line charge density. These are currently under study using the WARP code, and may also place limits on IRE generalized perveance at the final focus.

Computer simulation of beam dynamics plays an essential role in the analysis and design of the IRE. Areas of investigation are numerous. They include aberrations, longitudinal/transverse coupling, interactions through module impedance, mismatches from acceleration and errors, multiple beam interactions, neutralization and stripping in chamber, to name a few. See [4], [5] for further details. Validation of the computational tools on near-term experiments leads to confidence in future designs.

The reference IRE parameters describe an accelerator which would address nearly every non-target issue needed to proceed to the ETF. The high generalized perveance of thebeams would provide a rigorous test of individual 
beam acceleration, compression, and focusability. The final design will ultimately reflect all beam manipulations that would be found in a driver (e.g. if systems studies suggest that beam merging will be necessary in a driver, then an IRE will also be required to demonstrate beam merging). A number of chamber transport methods (including ballistic neutralized transport, channel transport, and self-pinch transport) will be tested. The final extrapolation to the higher ion energy in the ETF will rely on atomic cross-sections obtained from high-energy accelerators such as those at GSI, together with extrapolation of lower energy data from the IRE, theory and simulations. Technology issues of lifetime and maintainability will be demonstrated on the IRE and when necessary on small off-line component tests. Chamber technology issues may, to a large extent, be tested in separate facilities, although issues of driver/chamber interface (such as allowable stand-off distance between beam and shielding material) will be addressable in the IRE [15].

\section{Systems studies}

Computer aided optimization is also beginning to play an important role in the design of the machine. The systems code IBEAM (cf. [16, 17]) is being developed and used to find optimal designs. Figure 1 illustrates the variation in cost (relative to the case with the nominal parameters listed above) for an IBEAMgenerated design with parameters essentially the same as the reference accelerator, with a $5 \mathrm{~ns}$ pulse duration on target. In the figure, $\mathrm{M}$ is the design parameter divided by the nominal design parameter for each curve. $M=1$ is for the nominal design. The parameters varied were initial pulse duration (squares), quadrupole field (circles), number of beams (crosses), and transition energy from electric to magnetic quads (no symbol). 


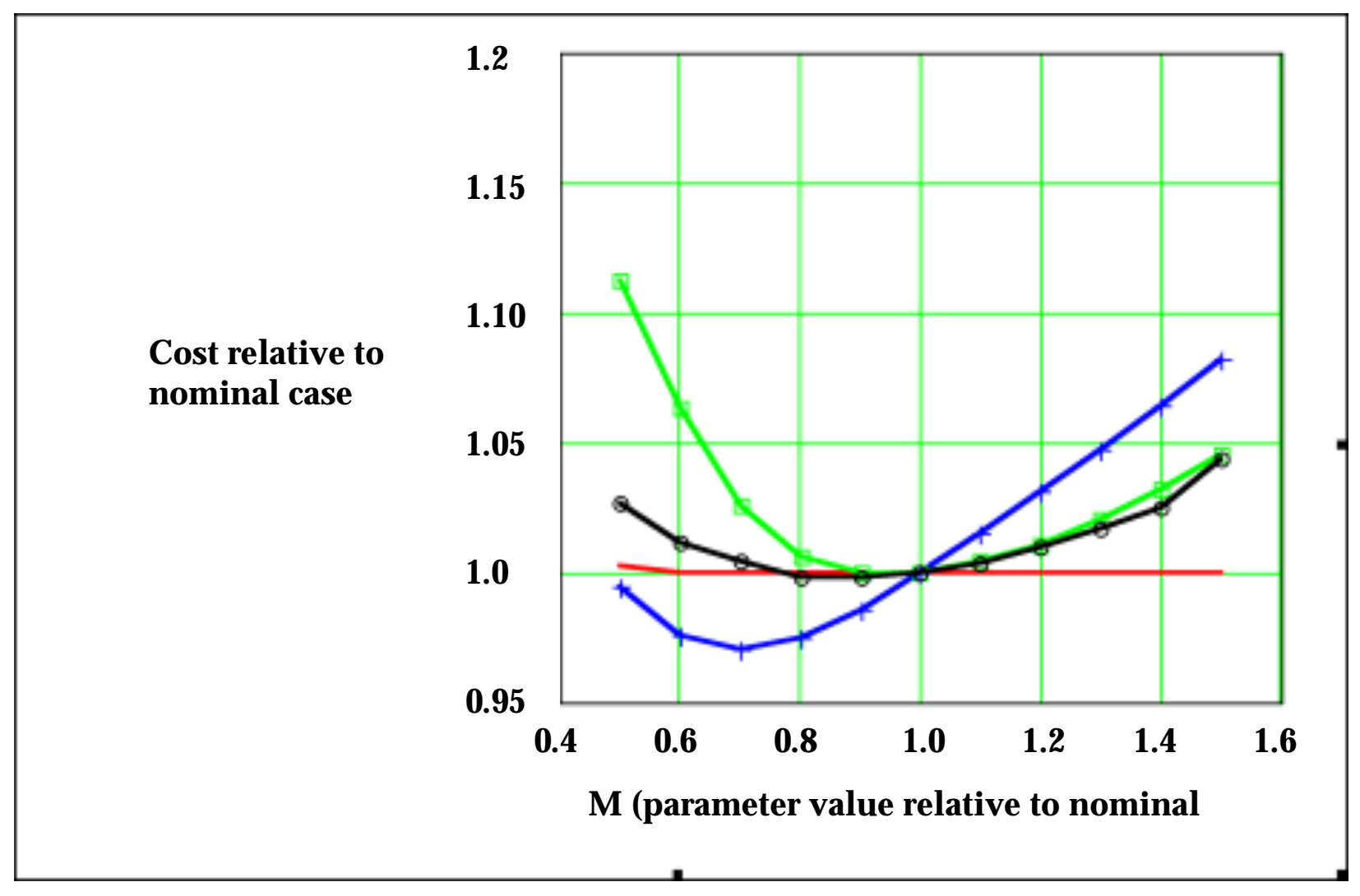

Figure 1. Relative cost vs. selected design parameters (relative to nominal). The nominal parameters are quadrupole field at winding (circles, nominal value 4T), initial pulse duration (squares, nominal value $6.69 \mu \mathrm{s}$ ), number of beams (crosses, nominal value 32 ) and transition energy from electric to magnetic (no symbol, nominal value $9.43 \mathrm{MeV}$ ).

Notice that only the number of beams appears not to be optimum in the design. However, the nominal number of beams is consistent with the spot size and the assumed degree of neutralization (98\%) which may not be the case with fewer beams. Also note that for the parameters shown, variations in cost are small (less than $12 \%$ ) indicating broad optima are likely in the final design.

\section{Summary and conclusions}

A multi-pronged Phase 1 research effort is laying the groundwork for the Integrated Research Experiment. Experiment, technology development, theory, simulation, and systems studies are all playing major roles in this Phase I research. The key research areas are: 1 . Source and injector (for investigation of a high brightness, multiple beam, low cost injector); 2 . High current transport (to examine effects at full driver-scale line charge density, including the maximization of the beam filling-factor and control of electrons); 3. Enabling technology development (low cost and high performance magnetic core material, superconducting magnetic quadrupole arrays, insulators, and pulsers); and 4 . Beam simulations and theory (for investigations of beam matching, specification 
of accelerator errors, studies of emittance growth, halo, and bunch compression, in the accelerator, and neutralization methods, stripping effects, spot size minimization in the chamber); and 5. Systems optimization (minimization of cost and maximization of pulse energy and beam intensity).

We have begun the process of designing, simulating, and optimizing the next major heavy-ion induction accelerator, the IRE. This accelerator facility will, in turn, help provide the basis to proceed to the next step in the development of IFE as an attractive source of fusion energy.

\section{References}

[1] R.O. Bangerter, "The Heavy Ion Fusion Program in the USA," these proceedings (2000).

[2] J.W. Kwan, D.N. Beck, F.M. Bieniosek, A. Faltens, E. Henestroza, L. Ahle, D.P. Grote, E. Halaxa, V. Karpenko, T.C. Sangster, W.B. Herrmannsfeldt, "Ion Sources and Injectors for Induction Linacs," these proceedings (2000).

[3] P.A. Seidl, "Experiments in the USA Virtual National Laboratory," these proceedings (2000).

[4] A. Friedman, "Beam Simulations for IRE and Driver-Status and Strategy," these proceedings (2000).

[5] D.P. Grote, A. Friedman, G.Craig, I. Haber, W.M.Sharp, "Progress Toward Source-to-Target Simulation," these proceedings (2000).

[6] C.H. Kim and L. Smith, "A design procedure for acceleration and bunching in an ion induction linac," Particle Accelerators, 18, p. 101, (1985).

[7] E.P. Lee, Heavy Ion Driven LMF Design Concept UC-421, LBL-31248 revised, HIFAN721, July (1995).

[8] A. Faltens, “HTE update,” LBNL HIFAR 468, (1996).

[9] E.P. Lee, T. J. Fessenden, L.J.Laslett, “Transportable Charge in a Periodic Alternating Gradient System," IEEE Trans. Nucl. Science, NS-26, p. 2489 (1985).

[10] E.P. Lee, “New IRE," private communication July 16, 1998, (and LBNL HIFAN note in preparation).

[11] E.P. Lee and J.W-K. Mark, "Spot Heating Calculation for a Heavy Ion Driven High Temperature Experiment," LBL-16890, HIFAN-226, April 1984. 
[12] B.Y. Sharkov, N.N. Alexeev, M.D. Churazov, A.A. Golubev, P.R. Zenkovich, D.G. Koshkarev, "Heavy Ion Fusion Energy Program in Russia," these proceedings (2000).

[13] C.Olson, "Chamber Transport," these proceedings (2000).

[14] A.Warwick and E.P. Lee, "Acceleration Errors in MBE-4 and in a Driver," HIFAR 214, (1988).

[15] P.F. Peterson, "HIF Liquid Hydraulics Scaling and Pocket Design, " these proceedings (2000).

[16] W.R. Meier, R.O.Bangerter, A. Faltens, "An Integrated Systems Model for Heavy Ion Drivers," Nuclear Instruments and Methods in Physics Research, A, 415, p. 249 (1998).

[17] W.R. Meier, J.J. Barnard, R.O. Bangerter, "Evaluating Heavy Ion Driver Design Options Using an Integrated Systems Model," these proceedings (2000).

Send proofs to:

John J. Barnard

Lawrence Livermore National Laboratory

P.O. Box 808, L-645

Livermore, CA 94551 USA

Phone: $925-423-0675$

Fax: 925-422-7390

Email: jjbarnard@llnl.gov 